\title{
Assessing organisational justice as a predictor of job satisfaction and employee engagement in Windhoek
}

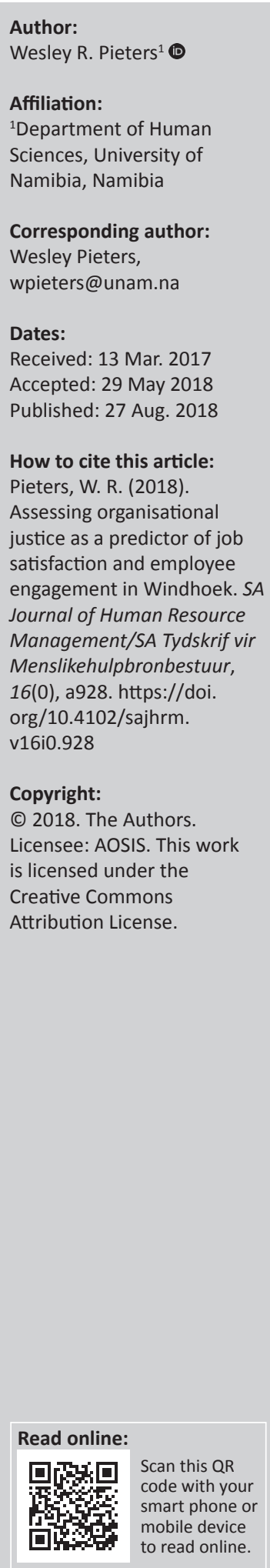

Orientation: Working in the service industry with similar products and services requires organisations to be proactive and efficient. Enhancing employees' levels of organisational justice is likely to influence job satisfaction and employee engagement.

Research purpose: The purpose of this study was to investigate the dimensions of organisational justice that best predict job satisfaction and employee engagement among employees in Windhoek, Namibia.

Motivation for the study: Poor service delivery is a concern within the service industry and this includes the banks and universities that operate in Windhoek. Having engaged employees is most likely going to improve the quality of service and customer satisfaction.

Research approach/design and method: A cross-sectional survey design was used, employing a questionnaire to collect data on the biographical details, organisational justice, job satisfaction and employee engagement of employees at a bank and university in Windhoek. The sample consisted of employees from a bank, Bank A $(n=106)$, and administrative staff at a university $(n=97)$.

Main findings: Significant predictors of employee engagement (work energy) were interpersonal organisational justice and intrinsic job satisfaction. Regarding employee engagement (work focus), intrinsic job satisfaction and extrinsic job satisfaction were the significant predictors.

Practical/managerial implications: Managers and supervisors need to regularly assess, monitor and enhance employees' perception of organisational justice, job satisfaction and employee engagement. Improving organisational justice within the workplace is likely to result in an increase in job satisfaction and employee engagement, resulting in increased productivity and customer satisfaction.

Contribution/value-add: The novelty of this study in Namibia will add to already existing knowledge within industrial and organisational psychology, pave the way for future research and guide the development of interventions aimed at keeping employees satisfied and engaged in their work.

\section{Introduction}

Employees working in the service industry may regard their jobs as challenging and exhausting. The manner in which employees or representatives from an organisation interact with clients will have a significant impact on the customers' experience (Bettencourt \& Brown, 1997). Furthermore, the nature of the interaction will also impact on customers' decision regarding whether to continue making use of the organisation's service or to look for another service provider. The consequences of poor customer service are related to tertiary institutions and the banking industry.

Ikhide (2000) indicated that banks are critical to a country's financial sector, and in Namibia they account for half of the country's financial assets. Considering that Namibia has five banks that offer similar services, it is important to identify how banks can remain competitive while at the same time remaining productive. Competitiveness and productivity are some of the main reasons why organisations go into business. Apart from the different advertising approaches or reduced banking fees, having the most satisfied and engaged workforce will likely add to that competitive advantage. Soltis, Agneessens, Sasovova and Labianca (2013) indicated that organisations are constantly working hard to retain their top talent, especially considering how much money and 
time is invested in developing employees to levels of effective functioning. Universities, like many other organisations, are faced with increased challenges without the necessary resources to deal with the challenges (Rothmann \& Jordaan, 2006). In order to maintain a competitive advantage and to overcome some of the challenges experienced by employees, apart from other positive experiences, these employees need to experience organisational justice.

Organisational justice can be defined as the perception of employees about fairness within the organisation (Greenberg, 2011). This subjective perception can contradict what the employer believes or does in terms of fairness. Organisational justice has different forms, namely distributive, procedural, informational and interpersonal justice. Organisational justice may also be considered to consist of distributive, procedural and interactional justice. Dajani (2015) found that when employees experience organisational justice they are also more likely to experience job satisfaction at the workplace. When employees perceive interactions to be fair at work they are likely to be more satisfied.

Job satisfaction can be regarded as the overall evaluation of employees regarding their jobs, characterised by gratification and positive feelings about their jobs. Job satisfaction can be determined by different components of the job, namely pay, benefits, collegial relations, advancement opportunities or the meaning they experience from doing their jobs (Judge \& Nammeyer-Mueller, 2012). Job satisfaction has been investigated as an antecedent or outcome variable.

Sehunoe, Viviers and Mayer (2015) found that when employees experience job satisfaction, they are also more likely to become more engaged in their work. Employee engagement is defined as a positive, motivational state of work-related well-being that is fulfilling and affective (Bakker, Schaufeli, Leiter, \& Taris, 2008). Rothbard and Patil (2012) explained engagement as the psychological presence of an employee in a role. This means that employees who are engaged experience positive emotions and work towards the goals of the organisation, especially if they identify with the specific role. These objectives would include providing quality customer service and ensuring that the objectives of the organisations are met more efficiently.

Rasheed, Khan and Ramzan (2013) indicated that organisational justice is a key factor for enhancing employee engagement within the organisation, and when improving employees' perception of organisational justice, organisations ultimately also increase their competitive position within the job market. Engaged employees also allow an organisation to achieve significant outcomes within their working environment.

\section{Purpose}

A number of studies (Alvi \& Abbasi, 2012; Biswas, Varma, \& Ramaswami, 2013; Dajani, 2015; Rasheed et al., 2013; Saks, 2006; Strom, Sears, \& Kelly, 2013; Tessema, 2014) have been conducted on the relationship between organisational justice and employee engagement, but a limited number, if any, has investigated the predictability of employee engagement by organisational justice. The same has been noted in relation to the relationship between job satisfaction and employee engagement. The researcher did not find any research regarding organisational justice, the relation between organisational justice, job satisfaction and employee engagement, nor has any study been found investigating the predictability of employee engagement by organisational justice or job satisfaction in Namibia. This study aims to investigate these relations but also the predictability of organisational justice and job satisfaction on employee engagement. The aim of this study is equally to replicate the study in different industries, trying to influence the perception of employers, importance and understanding of organisational justice within the world of work.

\section{Literature review Organisational justice and job satisfaction}

As noted earlier, organisational justice comprises of three forms of justice, namely, distributive, procedural and interactional justice (interpersonal and informational justice combined). This study will be defining organisational justice based on the three forms of justice. Distributive justice refers to the perception of fairness by employees in terms of how the outcomes within the organisation are distributed (rewards, recognition, pay). Procedural justice pertains to how fair the procedures are that have been used to determine these outcomes. Interactional justice refers to employees' perception of fairness in terms of interpersonal treatment they receive from their authority figures within the organisation (Greenberg, 2011).

In a longitudinal study by Kim, Lin and Leung (2015) conducted in Hong Kong on changes regarding the perception of employees about fairness, it was found that distributive justice at Time 1 had a correlation of 0.29 with job satisfaction and 0.53 at Time 2. Procedural justice had correlations of 0.33 at Time 1 and 0.43 at Time 2 with job satisfaction. Interactional justice also had correlations with job satisfaction, 0.27 at Time 1 and 0.46 at Time 2. This indicates that when employers invest time and effort in clarifying and educating employees on the procedures within organisations, communicating the outcomes of decisions and helping employees understand how decisions were reached, they are likely to increase their levels of perceived distributive, procedural and interactional justice. When these levels of perceived justice increase, they are more likely to experience higher levels of job satisfaction in their respective jobs.

Pinikahana and Happell (2004) referred to job satisfaction as a state that is impacted by the employees' personal characteristics, what they expect from the work and the organisation. In a study on talent management Gelens, Hofmans, Dries and Pepermans (2014) found a positive practical significant relation between job satisfaction and perceived procedural fairness. They also reported a positive practical significant relation between job satisfaction and 
perceived distributive justice. This means that if employees experience procedural and distributive justice in the organisation, perceiving procedures to be followed fairly and rewards and punishment to be distributed fairly, they are also more likely to experience job satisfaction in the organisation.

Organisational justice was shown to be positively related to job satisfaction in an investigation on employees in Malawi (McAuliffe, Manafa, Maseko, Bowie, \& White, 2009). Procedural justice (0.49), distributive justice (0.49), interpersonal justice (0.43) and informational justice (0.51) had a positive relation with job satisfaction (Lawson, Noblet, \& Rodwell, 2009). It was further found that distributive and interactional justice significantly influenced job satisfaction (Lopez-Cabarcos, Pinho, \& Vazques-Rodriguez, 2014). Al-Tit and Hunitie (2015) conducted research at an academic institution and found that organisational justice was also positively correlated to job satisfaction (0.47). Procedural justice (0.39) and distributive justice (0.51) had significant correlations with job satisfaction among employees working in Canada (Saks, 2006). These findings indicate that when employees perceive organisational justice within the organisation, if rewards and punishment are being distributed fairly, if procedures within the organisation are being followed and if the manner in which supervisors and colleagues interact is collegial, employees are likely to find more pleasure and satisfaction in their jobs. When working for an organisation that is regarded as treating employees fairly, employees are more likely to experience satisfaction in their work.

Considering the literature presenting a link between organisational justice and job satisfaction, the following hypotheses were developed:

Hypothesis 1: Organisational justice has a positive relation with job satisfaction.

Hypothesis 2: Organisational justice is a significant predictor of job satisfaction.

\section{Organisational justice and employee engagement}

In a study on bank employees conducted in Ethiopia by Tessema (2014), it was found that perceptions of organisational justice positively impacted on employees' level of engagement. It was further stated that when employees perceive fairness within the organisation they are also more likely to feel obliged to be fair in doing their work, resulting in higher levels of employee engagement. Alvi and Abbasi (2012) also undertook a similar study in Pakistan on banking employees and found distributive (0.56), procedural (0.41) and interactional justice $(0.43)$ to be positively correlated to employee engagement. When employees experience interactional justice, they perceive the manner in which supervisors and colleagues interact with them as fair and just. When you have colleagues and supervisors treating you with the necessary respect and dignity, you are also more likely to want to follow the instructions of such a supervisor or work collectively with these colleagues to achieve your organisational goals, becoming more engaged in the work that you are tasked to do.

In an online survey by Strom et al. (2013), distributive justice (0.44) and procedural justice (0.52) had positive correlations with employee engagement. This indicates that when employees perceive the distribution of rewards and punishment to be done fairly and justly, they are more likely to also become engaged in the work that they do in the organisation. Based on the equity theory of 1963 by Stacey Adams (Al-Zawahreh \& Al-Madi, 2012), when employees perceive an imbalance between inputs and outcomes, they are likely to find ways to re-establish equity. This means that when employees are treated unfairly (distributive justice, more punishment or fewer rewards), it is expected that these employees might try to find ways to reduce their inputs to justify the outcomes that they receive.

Conducting research on managers in India, Biswas et al. (2013) found that distributive (0.01) and procedural justice (0.39) showed positive correlations with employee engagement. In a study that set out to determine the antecedents and outcomes of employee engagement in Pakistan, Rasheed et al. (2013) reported that procedural justice (0.26) correlated positively with job engagement and organisational engagement (0.47). Distributive justice also had positive correlations with job engagement (0.19) and with organisational engagement (0.27). In an analysis of the antecedents and outcomes of employee engagement Saks (2006) found a positive correlation between procedural justice and job engagement (0.25) and organisational engagement (0.41). Distributive justice was also positively related to job engagement (0.22) and organisational engagement (0.33). In another study on employee engagement, Al-Tit and Hunitie (2015) found that organisational justice was positively related to employee engagement (0.53). Similarly, Dajani (2015) conducted research within the Egyptian banking sector and also found organisational justice to be positively correlated to employee engagement (0.44). When employees perceive the procedures used to determine outcomes as fair, meaning that the way or manner in which decisions within the organisations are made seems to be in line with organisational procedure, employees are more likely to become engaged in the work that they do in the organisation.

Based on the aforementioned literature on the link between organisational justice and employee engagement, the following hypotheses were developed:

Hypothesis 3: Organisational justice has a positive relation with employee engagement.

Hypothesis 4: Organisational justice is a significant predictor of employee engagement.

\section{Job satisfaction and employee engagement}

Bakker et al. (2008) indicated that employee engagement is characterised by vigour (high levels of energy in executing 
work tasks), dedication (remaining focused on completing the task even when it becomes challenging) and absorption (being able to work for long periods of time while being actively involved). Harter, Schmidt and Hayes (2002) indicated that job satisfaction and employee engagement are related to meaningful business outcomes, and in order for the business to be successful and productive, it must first impact on individual-level constructs.

Saks (2006) found that job satisfaction is positively related to job engagement (0.52) and organisational engagement (0.57). The same positive correlation was found between job satisfaction and employee engagement (0.43) (Brunetto, Teo, Shacklock, \& Farr-Wharton, 2012). Job satisfaction was also proven to have a positive correlation with vigour (0.44), dedication (0.50) and absorption (0.35) (Sehunoe et al., 2015). It was further noted that job satisfaction and employee engagement are strong predictors of organisational commitment (affective commitment). This indicates that when employees are satisfied in their jobs they are more likely to become engaged in their work and are more likely to want to remain with the organisation. Rothmann (2008) found that extrinsic satisfaction had a positive correlation with vigour (0.20) and dedication (0.21); intrinsic satisfaction also correlated positively with vigour $(0.16)$ and dedication (0.23). Al-Tit and Hunitie (2015) have shown that job satisfaction is an outcome of employee engagement.

Based on the aforementioned literature discussing the relation between employee engagement and job satisfaction, the following hypotheses were developed:

Hypothesis 5: Job satisfaction is positively related to employee engagement.

Hypothesis 6: Job satisfaction is a significant predictor of employee engagement.

\section{Method \\ Research approach}

Making use of a questionnaire, a cross-sectional research design was used to collect data on the biographical variables of employees, organisational justice, job satisfaction and employee engagement (Creswell, 2003). Research assistants approached institutions that provided a service to customers and these institutions provided approval to conduct the research. These organisations were approached at random and research was only conducted where and when approval was granted.

\section{Participants}

Making use of convenience sampling, participants who were fluent in English were included from a bank and a university in Windhoek, Namibia. From Bank A, 106 participants $(52.2 \%)$ and 97 participants from the university (47.8\%) took part in the study. In total, 240 questionnaires were distributed and 203 completed questionnaires were returned. The distribution between males and females was fairly even with
$45.3 \%$ males $(n=92)$ and $54.7 \%$ females $(n=111)$. The larger group in terms of age is of participants between the ages of 24 and 30 years $(n=85,41.9 \%)$, with only five participants in the age category of 51 and older $(2.5 \%)$. The participants had worked for approximately $1-2$ years $(n=56,27.6 \%)$, and 12 participants (5.9\%) had worked for 7-8 years. Looking at marital status, $69.5 \%(n=141)$ of the participants were single, 26.6\% $(n=54)$ were married and 3.9\% $(n=8)$ were divorced. Regarding qualifications, 91 participants (44.8\%) had completed Grade 12 and $0.5 \%(n=1)$ had obtained postdoctoral qualifications. Regarding the number of dependents, $90(44.3 \%)$ had no dependents and only $1.5 \%(n=3)$ had $5-6$ dependents. The remainder of the biographical information is presented in Table 1 .

\section{Measuring instruments}

Biographical information was collected using a questionnaire developed by the researcher to get information regarding the participants' sex, age, marital status, qualifications, tenure and dependents within the two organisations.

Organisational justice was measured using the organisational justice measure developed by Colquitt (2001) measuring procedural, distributive, interpersonal and informational justice. This instrument measures procedural justice by using seven items ('to what extent have those procedures been free from bias?'), four items measuring distributive justice

TABLE 1: Biographical details of sample $(n=203)$.

\begin{tabular}{|c|c|c|c|}
\hline Item & Category & Frequency & Percentage \\
\hline \multirow[t]{2}{*}{ Sex } & Male & 92 & 45.3 \\
\hline & Female & 111 & 54.7 \\
\hline \multirow[t]{7}{*}{ Age (in years) } & $18-23$ & 35 & 17.2 \\
\hline & $24-30$ & 85 & 41.9 \\
\hline & $31-35$ & 32 & 15.8 \\
\hline & $36-40$ & 21 & 10.3 \\
\hline & $41-45$ & 17 & 8.4 \\
\hline & $46-50$ & 8 & 3.9 \\
\hline & 51 and older & 5 & 2.5 \\
\hline \multirow[t]{3}{*}{ Marital status } & Single & 141 & 69.5 \\
\hline & Married & 54 & 26.6 \\
\hline & Divorced & 8 & 3.9 \\
\hline \multirow[t]{5}{*}{ Qualification } & Grade 12 & 91 & 44.8 \\
\hline & Honours degree & 84 & 41.4 \\
\hline & MA degree & 24 & 11.8 \\
\hline & $\mathrm{PhD}$ & 3 & 1.5 \\
\hline & Post-doctoral & 1 & 0.5 \\
\hline \multirow{6}{*}{ Tenure } & Less than 1 year & 36 & 17.7 \\
\hline & $1-2$ years & 56 & 27.6 \\
\hline & $3-4$ years & 43 & 21.2 \\
\hline & $5-6$ years & 25 & 12.3 \\
\hline & $7-8$ years & 12 & 5.9 \\
\hline & 9 years and more & 31 & 15.3 \\
\hline \multirow[t]{4}{*}{ Dependents } & None & 90 & 44.3 \\
\hline & $1-2$ & 78 & 38.4 \\
\hline & $3-4$ & 32 & 15.8 \\
\hline & $5-6$ & 3 & 1.5 \\
\hline \multirow[t]{2}{*}{ Organisation } & Bank A & 106 & 47.8 \\
\hline & University & 97 & 47.8 \\
\hline Total & & 203 & 100.0 \\
\hline
\end{tabular}


('to what extent is your [outcome] justified, given your performance?'), interpersonal justice being measured by four items ('to what extent has he/she treated you with dignity?'), with informational justice being measured by five items ('to what extent has he/she communicated details in a timely manner?'). This instrument is a self-report questionnaire making use of a Likert-scale response format ranging from 1 (to a very small extent) to 5 (to a very large extent). Cronbach's alphas of 0.86 and 0.90 were also recorded for procedural justice and interpersonal justice, respectively, indicating the reliability of this instrument.

Employee engagement was measured using the Utrecht Work Engagement Scale developed by Schaufeli, Bakker and Salanova (2006), making use of 17 items measuring vigour ('I am bursting with energy in my work'), dedication ('I find the work that I do full of meaning and purpose') and absorption ('time flies when I am working'). This is a self-report questionnaire with responses ranging from 0 (never) to 6 (every day), having reported Cronbach's alphas of 0.70 (Simons \& Buitendach, 2013).

Job satisfaction was measured using the Revised Minnesota Job Satisfaction Questionnaire developed by Weiss, Dawis, England and Lofquist (1967). The instrument measures intrinsic and extrinsic job satisfaction ('the working conditions', 'the praise I get for doing a good job'). This is also a self-report questionnaire with response items ranging between 'very dissatisfied' and 'very satisfied'. Pieters (2015) reported Cronbach's alphas ranging between 0.70 and 0.77 for autonomy, social, advancement and intrinsic job satisfaction.

\section{Design}

Research assistants were employed to help in conducting the study, and permission to conduct the study was obtained from the participating bank and university. Participants were individually approached for permission to participate in the study. An information sheet and a consent form were distributed, and informed consent was then granted on an individual basis. The data were analysed using SPSS; no participants were harmed during the research; participants' information was anonymised and kept confidential. Furthermore, participants were in no way disadvantaged if deciding not to participate or to withdraw from the study. The questionnaires are kept in a safe place for safety and future consideration.

\section{Analysis}

Making use of SPSS version 24.0 (SPSS, 2016) the data were analysed. Cronbach's alpha coefficients $(\alpha)$ were used to determine the internal consistency of the measuring instruments; Pearson correlation coefficients were used to determine the relationship between the variables. Descriptive statistics were also used to describe the means and standard deviations (SDs). Multiple regression analyses were used to investigate whether organisational justice predicted job satisfaction and employee engagement. It was also decided to set the value of significance at $95 \%$ confidence interval level $(p<0.05)$. Effect sizes were used to determine the practical significance of the findings (Steyn, 1999), while a cut-off point of 0.30 (medium effect) was set for the practical significance of the correlation coefficient (Cohen, 1988).

\section{Results \\ Descriptive statistics and correlations}

The means, SD, Cronbach's alpha and correlations were analysed and recorded in Table 2.

Cronbach's alphas were obtained on all the measuring instruments and were found to range between 0.68 and 0.86. Resi and Judd (2000) indicated that Cronbach's alphas between 0.80 and 0.60 are acceptable for research.

Means and SDs were analysed to describe the data. A mean score of 18.00 was recorded for procedural justice and 14.85 for interpersonal justice. As part of job satisfaction, a mean score of 23.71 was recorded for intrinsic job satisfaction and a mean score of 25.44 for extrinsic job satisfaction. For employee engagement, a mean score of 13.75 was recorded for employee engagement (work energy) and a mean score of 15.58 for employee engagement (work focus). It terms of the SD, 4.93 was recorded for procedural justice and 3.37 for interpersonal justice. An SD of 4.02 was recorded for intrinsic job satisfaction and 5.26 for extrinsic job satisfaction. For employee

\begin{tabular}{llllllll}
\multicolumn{2}{l}{ TABLE 2: Descriptive statistics and Pearson correlation coefficient. } \\
\hline
\end{tabular}

SD, standard deviation; PJ, procedural justice; INTJ. interpersonal justice; INTJS, intrinsic job satisfaction; EXTJS, intrinsic job satisfaction; EE (energy), employee engagement (work energy); EE (focus), employee engagement (work focus).

$\alpha$, alpha coefficients.

$*$, statistically significant: $p \leq 0.05$.

$\dagger$, practically significant correlation (medium effect): $0.30 \leq r \leq 0.49$; $\ddagger$, practically significant correlation (large effect): $r \geq 0.50$. 
engagement (work energy) an SD of 3.45 was reported and 5.93 for employee engagement (work focus).

Making use of Pearson correlation coefficients, it was found that procedural justice had a positive correlation with interpersonal justice $(r=0.41, p<0.05$; medium effect); with intrinsic job satisfaction $(r=0.35, p<0.05$; medium effect); and with extrinsic job satisfaction $(r=0.44, p<0.05$; medium effect). Interpersonal justice was also found to be positively related to intrinsic job satisfaction $(r=0.41, p<0.05$; medium effect); with extrinsic job satisfaction $(r=0.55, p<0.05$; large effect); supporting Hypothesis 1. Procedural justice had a positive correlation with employee engagement (work energy) ( $r=0.22, p<0.05$; statistically significant) and with employee engagement (work focus) $(r=0.37, p<0.05$; medium effect). Interpersonal justice was also found to be positively related to employee engagement (work energy) $(r=0.38, p<0.05$; medium effect) and with employee engagement (work focus) ( $r=0.36, p<0.05$; medium effect), thereby supporting Hypothesis 3. Intrinsic job satisfaction correlated positively with employee engagement (work energy) ( $r=0.57, p<0.05$; large effect) and with employee engagement (work focus) ( $r=0.50, p<0.05$; large effect). Extrinsic job satisfaction also had positive correlation with employee engagement (work energy) $(r=0.40, p<0.05$; medium effect) and with employee engagement (work focus) ( $r=0.51, p<0.05$; large effect), hence supporting Hypothesis 5.

\section{Multiple regression analyses}

Multiple regression analyses were carried out to test Hypotheses 2, 4 and 6. In the first model, extrinsic job satisfaction was used as the dependent variable, with procedural justice and interpersonal justice as the independent variables in Step 1. The results are reported in Table 3.

From Table 3 we can see that including procedural justice and interpersonal justice at the first step of the regression analysis produced a statistically significant model $\left(F_{(2,200)}=56.82\right.$; $p<0.00)$ and accounted for $36 \%$ of the variance. It appears that procedural justice $(\beta=0.26 ; t=4.18 ; p<0.00)$ and interpersonal justice $(\beta=0.45 ; t=7.22 ; p<0.00)$ are significant predictors of extrinsic job satisfaction.

Multiple regression analyses were performed in order to identify the significant predictors in relation to the hypotheses of this study. The first model analysed used intrinsic job satisfaction as the dependent variable and procedural justice and interpersonal justice as the independent variables (Model 1). The results are reported in Table 4.

As can be seen from Table 4, including procedural justice and interpersonal justice at the first step of the regression analysis produced a statistically significant model $\left(F_{(2,200)}=25.83\right.$; $p<0.00)$ and accounted for $20 \%$ of the variance. It appears that procedural justice $(\beta=0.22 ; t=3.20 ; p<0.02)$ and interpersonal justice $(\beta=0.32 ; t=4.55 ; p<0.00)$ are significant predictors of intrinsic job satisfaction.

The first model analysed used employee engagement (work energy) as the dependent variable and procedural justice and interpersonal justice were the independent variables (Model 1). Intrinsic job satisfaction and extrinsic job satisfaction in Model 2. The results are reported in Table 5.

As shown in Table 5, including procedural justice and interpersonal justice at the first step of the regression analysis produced a statistically significant model $\left(F_{(2,200)}=17.96\right.$; $p<0.00)$ and accounted for $14 \%$ of the variance. It appears that procedural justice $(\beta=0.08 ; t=1.11 ; p<0.27)$ is not a significant predictor and that interpersonal justice $(\beta=0.35$; $t=4.91 ; p<0.00)$ is a significant predictor of employee engagement (work energy). In the second step of the regression analysis, job satisfaction was entered, and it produced an insignificant model. Job satisfaction being part of the model $\left(F_{(4,198)}=27.49 ; p<0.57\right)$ explained an additional $34 \%$ of the total variance. Looking at this together with job satisfaction, interpersonal justice $(\beta=0.16 ; t=2.25 ; p<0.03)$

TABLE 3: Multiple regression analysis with extrinsic job satisfaction being the dependant variable and procedural justice and interpersonal justice the independent variables.

\begin{tabular}{|c|c|c|c|c|c|c|c|c|}
\hline \multirow[t]{2}{*}{ Model } & \multicolumn{2}{|c|}{ Unstandardised coefficients } & \multirow{2}{*}{$\begin{array}{l}\text { Standardised coefficients } \\
\qquad(\beta)\end{array}$} & \multirow[t]{2}{*}{$t$} & \multirow[t]{2}{*}{$p$} & \multirow[t]{2}{*}{$\boldsymbol{F}$} & \multirow[t]{2}{*}{$R^{2}$} & \multirow[t]{2}{*}{$\Delta R^{2}$} \\
\hline & $B$ & SE & & & & & & \\
\hline (Constant) & 10.10 & 1.47 & - & 6.88 & 0.00 & 56.82 & 0.36 & 0.36 \\
\hline Procedural justice & 0.28 & 0.07 & 0.26 & 4.18 & $0.00 * *$ & - & - & - \\
\hline Interpersonal justice & 0.70 & 0.10 & 0.45 & 7.22 & $0.00 * *$ & - & - & - \\
\hline
\end{tabular}

$t$, test; $p$, probability value; $F$, overall significance; $R^{2}$, percentage variance explained; $\Delta R^{2}$, change in percentage variance explained; $\mathrm{B}$, regression coefficient; $\mathrm{SE}$, standard error. Dependent variable: extrinsic job satisfaction.

$*, p \leq 0.05 ; * *, p \leq 0.01$.

TABLE 4: Multiple regression analysis with intrinsic job satisfaction being the dependent variable and procedural justice and interpersonal justice the independent variables.

\begin{tabular}{|c|c|c|c|c|c|c|c|c|}
\hline \multirow[t]{2}{*}{ Model } & \multicolumn{2}{|c|}{ Unstandardised coefficients } & \multirow{2}{*}{$\begin{array}{l}\text { Standardised coefficients } \\
\qquad(\beta)\end{array}$} & \multirow[t]{2}{*}{$T$} & \multirow[t]{2}{*}{$p$} & \multirow[t]{2}{*}{$F$} & \multirow[t]{2}{*}{$R^{2}$} & \multirow[t]{2}{*}{$\Delta R^{2}$} \\
\hline & $B$ & SE & & & & & & \\
\hline (Constant) & 14.90 & 1.25 & - & 11.90 & 0.00 & 25.83 & 0.21 & 0.20 \\
\hline Procedural justice & 0.18 & 0.06 & 0.22 & 3.20 & $0.02 *$ & - & - & - \\
\hline Interpersonal justice & 0.38 & 0.08 & 0.32 & 4.55 & $0.00 * *$ & - & - & - \\
\hline
\end{tabular}

$t$, test; $p$, probability value; $F$, overall significance; $R^{2}$, percentage variance explained; $\Delta R^{2}$, change in percentage variance explained; $\mathrm{B}$, regression coefficient; $\mathrm{SE}$, standard error. $*, p \leq 0.05 ; * *, p \leq 0.01$. 
TABLE 5: Multiple regression analysis with employee engagement (work energy) being the dependent variable and procedural justice, interpersonal justice, intrinsic job satisfaction and extrinsic job satisfaction the independent variables.

\begin{tabular}{|c|c|c|c|c|c|c|c|c|}
\hline \multirow[t]{2}{*}{ Model } & \multicolumn{2}{|c|}{ Unstandardised coefficients } & \multirow{2}{*}{$\begin{array}{l}\text { Standardised coefficients } \\
\qquad(\beta)\end{array}$} & \multirow[t]{2}{*}{$t$} & \multirow[t]{2}{*}{$p$} & \multirow[t]{2}{*}{$F$} & \multirow[t]{2}{*}{$R^{2}$} & \multirow[t]{2}{*}{$\Delta R^{2}$} \\
\hline & $B$ & SE & & & & & & \\
\hline (Constant) & 7.42 & 1.11 & - & 6.68 & 0.00 & 17.96 & 0.15 & 0.14 \\
\hline Procedural justice & 0.06 & 0.05 & 0.08 & 1.11 & 0.27 & - & - & - \\
\hline Interpersonal justice & 0.36 & 0.07 & 0.35 & 4.91 & $0.00 * *$ & - & - & - \\
\hline (Constant) & 0.73 & 1.29 & - & 0.56 & 0.57 & 27.49 & 0.36 & 0.34 \\
\hline Procedural justice & -0.35 & 0.05 & -0.05 & -0.76 & 0.45 & - & - & - \\
\hline Interpersonal justice & 0.16 & 0.07 & 0.16 & 2.25 & $0.03 *$ & - & - & - \\
\hline Intrinsic job satisfaction & 0.41 & 0.06 & 0.47 & 7.03 & $0.00 * *$ & - & - & - \\
\hline Extrinsic job satisfaction & 0.06 & 0.05 & 0.10 & 1.26 & 0.21 & - & - & - \\
\hline
\end{tabular}

$t$, test; $p$, probability value; $F$, overall significance; $R^{2}$, percentage variance explained; $\Delta R^{2}$, change in percentage variance explained; $\mathrm{B}$, regression coefficient; $\mathrm{SE}$, standard error.

Dependent variable: work engagement (work energy).

$*, p \leq 0.05 ; * *, p \leq 0.01$.

TABLE 6: Multiple regression analysis with employee engagement (work focus) being the dependent variable and procedural justice, interpersonal justice, intrinsic job satisfaction and extrinsic job satisfaction the independent variables.

\begin{tabular}{|c|c|c|c|c|c|c|c|c|}
\hline \multirow[t]{2}{*}{ Model } & \multicolumn{2}{|c|}{ Unstandardised coefficients } & \multirow{2}{*}{$\begin{array}{l}\text { Standardised coefficients } \\
\text { ( } \beta \text { ) }\end{array}$} & \multirow[t]{2}{*}{$t$} & \multirow[t]{2}{*}{$p$} & \multirow[t]{2}{*}{$F$} & \multirow[t]{2}{*}{$R^{2}$} & \multirow[t]{2}{*}{$\Delta R^{2}$} \\
\hline & $B$ & SE & & & & & & \\
\hline (Constant) & 3.14 & 1.87 & - & 1.68 & 0.94 & 23.80 & 0.19 & 0.18 \\
\hline Procedural justice & 0.32 & 0.08 & 0.27 & 3.83 & $0.00 * *$ & - & - & - \\
\hline Interpersonal justice & 0.49 & 0.12 & 0.25 & 3.65 & $0.00 * *$ & - & - & - \\
\hline (Constant) & -6.79 & 2.22 & - & -3.06 & 0.03 & 27.42 & 0.36 & 0.34 \\
\hline Procedural justice & 0.15 & 0.08 & 0.13 & 1.92 & 0.56 & - & - & - \\
\hline Interpersonal justice & 0.06 & 0.13 & 0.03 & 0.44 & 0.66 & - & - & - \\
\hline Intrinsic job satisfaction & 0.45 & 0.10 & 0.30 & 4.50 & $0.00 * *$ & - & - & - \\
\hline Extrinsic job satisfaction & 0.32 & 0.09 & 0.29 & 3.79 & $0.00 * *$ & - & - & - \\
\hline
\end{tabular}

$t$, test; $p$, probability value; $F$, overall significance; $R^{2}$, percentage variance explained; $\Delta R^{2}$, change in percentage variance explained; $\mathrm{B}$, regression coefficient; $\mathrm{SE}$, standard error. Dependent variable: work engagement (work focus).

$*, p \leq 0.05 ; * *, p \leq 0.01$.

and intrinsic job satisfaction $(\beta=0.47 ; t=7.03 ; p<0.00)$ predicted employee engagement (work energy).

Multiple regression analyses were performed. The first model used employee engagement (work focus) as the dependent variable and procedural justice and interpersonal justice as the independent variables (Model 1). Intrinsic job satisfaction and extrinsic job satisfaction in Model 2. The results are reported in Table 6.

It can be seen from the data in Table 6 that entry of procedural justice and interpersonal justice at the first step of the regression analysis did not produce a statistically significant model $\left(F_{(2,200)}=23.80 ; p<0.09\right)$ and accounted for $18 \%$ of the variance. It appears that procedural justice $(\beta=0.32 ; t=3.83$; $p<0.00)$ and interpersonal justice $(\beta=0.49 ; t=3.65 ; p<0.00)$ are significant predictors of employee engagement (work focus). In the second step of the regression analysis, job satisfaction was entered, and it produced a significant model. Job satisfaction being part of the model $\left(F_{(4,198)}=27.42\right.$; $p<0.00$ ) explained an additional $34 \%$ of the total variance. Looking at this together with job satisfaction, intrinsic job satisfaction $(\beta=0.30 ; t=4.50 ; p<0.00)$ and extrinsic job satisfaction $(\beta=0.29 ; t=3.79 ; p<0.00)$ predicted employee engagement (work focus). In summary, it has been shown from this discussion that:

- Procedural justice predicted intrinsic job satisfaction $(\beta=0.22 ; t=3.20 ; p<0.02)$, intrinsic job satisfaction predicted employee engagement (work energy) $(\beta=0.47$; $t=7.03 ; p<0.00)$ and intrinsic job satisfaction predicted employee engagement (work focus) $(\beta=0.30 ; t=4.50$; $p<0.00)$.

- Procedural justice $(\beta=0.26 ; t=4.18 ; p<0.00)$ predicted extrinsic job satisfaction, and extrinsic job satisfaction predicted employee engagement (work focus) $(\beta=0.29$; $t=3.79 ; p<0.00$ ).

- Procedural justice predicted employee engagement (work focus) $(\beta=0.27 ; t=3.83 ; p<0.00)$.

- Interpersonal justice predicted intrinsic job satisfaction $(\beta=0.32 ; t=4.55 ; p<0.00)$, intrinsic job satisfaction predicted employee engagement (work energy) $(\beta=0.47$; $t=7.03 ; p<0.00)$ and intrinsic job satisfaction predicted employee engagement (work focus) $(\beta=0.30 ; t=4.50$; $p<0.00)$.

- Interpersonal justice predicted extrinsic job satisfaction $(\beta=0.45 ; t=7.22 ; p<0.00)$; extrinsic job satisfaction predicted employee engagement (work focus) $(\beta=0.29$; $t=3.79 ; p<0.00)$.

- Interpersonal justice predicted employee engagement (work energy) $(\beta=0.35 ; t=4.91 ; p<0.00)$.

- Interpersonal justice predicted employee engagement (work focus) $(\beta=0.25 ; t=3.65 ; p<0.00)$.

\section{Discussion}

\section{Outline of the results}

The first hypothesis of this study, organisational justice has a positive relation with job satisfaction, was accepted. Procedural justice had a positive correlation with intrinsic job satisfaction and extrinsic job satisfaction. Interpersonal justice also had 
positive correlations with intrinsic job satisfaction and extrinsic job satisfaction. Interpersonal justice was found to be a stronger predictor of extrinsic job satisfaction and intrinsic job satisfaction over procedural justice, supporting Hypothesis 2. Gelens et al. (2014) also found positive correlations between procedural, distributive justice and job satisfaction. This indicates that when the organisational procedures are followed and applied consistently and fairly, when supervisors and managers treat employees with the necessary respect and dignity, employees are more likely to be satisfied in their jobs.

Several studies, including Al-Tit and Hunitie (2015), Lawson et al. (2009), Lopez-Cabarcos et al. (2014), McAuliffe et al. (2009) and Saks (2006), also found positive correlations between components of organisational justice and job satisfaction. What is interesting to note is that these studies also highlighted the importance of interpersonal justice within the organisation and how it also has a positive correlation with job satisfaction. Once managers or supervisors make a decision, informing employees about how that decision was made and treating them with the necessary respect and dignity enhances interpersonal justice. Another critical component that impacts on job attitudes is the relations supervisors, managers and colleagues have with each other at work. Employees spend 160 hours per month at work, and having negative relations or interactions with colleagues can negatively impact on the levels of job satisfaction.

Procedural justice had a positive correlation with employee engagement (work energy) and with employee engagement (work focus). Interpersonal justice was also found to be positively related to employee engagement (work energy) and with employee engagement (work focus), supporting Hypothesis 3. Tessema (2014) also found similar results and stated that when employees experience fairness and justice within the workplace, they are likely to feel obligated to be fair in doing the work that they are paid for (employee engagement). Interpersonal justice was found to be a significant predictor of work energy (employee engagement), supporting Hypothesis 4 partially. Procedural justice was not found to be a significant predictor of work focus (employee engagement); equally, procedural justice and interpersonal justice were also not found to be significant predictors of work energy (employee engagement). Alvi and Abbasi (2012) found interactional justice to be important in enhancing employees' levels of engagement in their work. When supervisors and managers treat employees with the necessary respect and dignity (interactional justice), they are more likely to follow and execute instructions from these supervisors and managers (employee engagement). It was also found that distributive justice correlated positively to employee engagement. Considering the equity theory by Stacey Adams in 1963 (Al-Zawahreh \& Al-Madi, 2012), when rewards and punishment are not distributed fairly, employees will likely try and find ways to re-establish this imbalance between inputs and outcomes. This means that when supervisors favour certain employees, ensuring that these employees get more rewards and less punishment when compared to other employees, the employees who experience lower levels of distributive injustice will likely become disengaged from their work. This positive correlation between organisational justice and employee engagement was also supported by studies conducted in India (Biswas et al., 2013), Pakistan (Rasheed et al., 2013) and Egypt (Dajani, 2015) and by studies conducted by Al-Tit and Hunitie (2015), Saks (2006) and Strom et al. (2013).

Intrinsic job satisfaction correlated positively with employee engagement (work energy) and with employee engagement (work focus). Extrinsic job satisfaction also had positive correlation with employee engagement (work energy) and with employee engagement (work focus), supporting Hypothesis 5. Intrinsic job satisfaction was found to be a significant predictor for employee engagement (work energy). Intrinsic job satisfaction and extrinsic job satisfaction were found to be significant predictors of employee engagement (work focus), thereby supporting Hypothesis 6 . These findings are also supported by studies conducted by Al-Tit and Hunitie (2015), Brunetto et al. (2012) and Saks (2006). Rothmann (2008) and Sehunoe et al. (2015) found positive correlations between job satisfaction and vigour, dedication and absorption. This means that when employees are satisfied in their jobs they are more likely to become more engaged in the work that they do. They would experience high levels of energy and mental resilience (vigour); they would be more involved in the work that they do, experience pride, inspiration, enthusiasm and feel like they were making a positive contribution in the work that they do (dedication); they would be fully concentrated on, happy and engrossed (taken in) by their work (absorption) (Bakker et al., 2008).

Kim et al. (2015) found that the perception of justice decreases over time especially for newcomers in an organisation. After the honeymoon phase when joining a new organisation, employees perceive lower levels of organisational justice. Resultantly, employers need to clarify unrealistic expectations, establish fair procedures for allocating rewards and improve communication about procedures and decisions made. When employers improve employees' perception of organisational justice, employees will be more satisfied in their jobs. Overall performance was found to be positively related to distributive justice (0.22) and procedural justice (0.46) (Kassahun, 2005). This supports the importance of organisational justice, indicating how it also impacts on organisational performance.

Brunetto et al. (2012) suggested that possible factors that could influence job satisfaction levels of employees are inadequate supervisory resourcing and support, as well as unrealistic performance targets. This means that when supervisors do not provide the necessary resources and support to employees while having unrealistic work expectations, it could result in employees becoming dissatisfied in their work.

Rothmann and Rothmann (2010) indicated that work role fit was the best predictor of employee engagement. Job 
resources were also found to be positively related to employee engagement. Organisational support and growth opportunities were the best predictors of vigour, dedication and absorption. It is thus suggested that organisations should put more emphasis on employment practices to ensure that the best-suited candidates are employed in the positions that best fit their abilities and skills. Working in an environment that provides the necessary resources (physical, emotional and cognitive) to execute their duties allows for improved employee engagement. Having policies and work practices in place that support employees, allowing employees to become part of decision-making within the organisation, identifying the needs of the employees and developing career growth paths for advancement (remuneration, promotion and training) also impacts positively on employee engagement.

\section{Practical implications}

Managers and organisations need to ensure that when they distribute rewards and punishments, it is done fairly and consistently. It is also important for managers and organisations to apply workplace policies consistently and fairly, giving the same outcomes for the same actions. Gelens et al. (2014), as with this study, found that when employees perceive distributive and procedural justice within the organisation, they are more likely to become more satisfied in their jobs.

Ensuring that employees become more engaged and perceive organisational justice is not a once-off process, but rather one that requires continuous assessment, monitoring and improvement (Kim et al., 2015; Rasheed et al., 2013). It is thus suggested that organisations should monitor employees' engagement levels regularly and improve where needed. The same can be said about employees' levels of perceived organisational justice. When employees do not know or understand how and why certain outcomes were reached, they might perceive these outcomes as being unfair even though the organisation is handling procedures fairly and applying workplace policies consistently.

To keep employees satisfied, conduct regular assessments and identify what would make your employees satisfied. The requirements for job satisfaction are not the same for all employees nor for all organisations. Each organisation and employee will have different aspects that satisfy them in their work. Boonzaier, Ficker and Rust (2001) indicated that in order for employees to be motivated and satisfied in their jobs, the jobs need to have five job characteristics. These job characteristics are task identity, the degree to which an employee can identify with a complete or identifiable piece of work, from start to finish; task significance has to do with the degree to which the job has an impact on the lives or work of other people, in the organisation or the external environment. Skill variety refers to the degree to which the employees can use different skills and talents to execute their duties at work. Autonomy can be defined as the degree to which the job allows you to be able to decide, having substantial freedom, independence and discretion in deciding how to execute your duties at work. Feedback refers to the extent to which the job requires you to execute your work with direct and clear information about the effectiveness of your work performance. Job resources and support, opportunities for advancement (Marais, de Klerk, Nel, \& de Beer, 2014), supportive colleagues and supervisors (Okediji, Etuk, \& Anthony, 2011) and total rewards (Smit, Stanz, \& Bussin, 2015) may influence job satisfaction of employees.

In order for businesses to become successful and productive, they need to focus on individual-level constructs such as job satisfaction and employee engagement (Harter et al., 2002). One way of enhancing job satisfaction and employee engagement could be to start with organisational justice. Organisational justice can be enhanced by ensuring that rewards and punishment are distributed fairly within the organisation and ensuring that organisational procedures are followed when making decisions that impact on the employees. Managers and supervisors need to communicate these decisions, but they should ensure that the employees have been educated about these policies and procedures. Another measure could be to ensure that managers and supervisors treat employees with the necessary respect and dignity that would not only enhance employees' level of job satisfaction but also make employees more engaged in their work.

\section{Limitations}

Some of the limitations experienced when conducting this study include limited access to the bank because of gatekeepers. In addition, some questionnaires were not completed in full and were excluded from this study. Data were collected over a period of a few months because of time constraints.

\section{Recommendations}

This research has thrown up many questions in need of further investigation. It is therefore recommended that a similar study should be conducted on a long-term basis (longitudinal study) to solidify the findings in this study. Further research could employ a quasi-experimental approach to explore the impact of educating employees about workplace policies and procedures, being informed about the information used to reach certain outcomes to test how organisational justice can be improved with education, information sharing and transparency.

\section{Conclusion}

Rasheed et al. (2013) indicated that because employee engagement is such a critical factor for an organisation to achieve significant outcomes, it should be measured, monitored and improved on a regular basis. When enhancing employees' perception of organisational justice (distributive, procedural and interactional justice), organisations are also enhancing employee engagement within the organisation and improving overall performance (Kassahun, 2005). 
Managers need to understand that in order for employees to become more engaged, managers and supervisors need to provide resources and benefits that will motivate employees to want to do more. Some of the factors that might positively influence employees' level of engagement include organisational justice, job satisfaction, social support and job characteristics (Saks, 2006). It is also critical to note that the same motivating factors might not work for all employees, meaning that organisations need to identify what resources and benefits would make employees more likely to become more engaged in their work.

This study found that procedural justice and interpersonal justice are significant predictors of intrinsic job satisfaction, extrinsic job satisfaction and employee engagement (work energy and work focus). If organisations could introduce measures of addressing organisational justice within the workplace, they would be attending to the employees' levels of job satisfaction and enhance their levels of engagement, thus resulting in increased productivity and customer satisfaction.

\section{Acknowledgements}

The author would like to thank his research students, A. Norich and N. Neshuku, for assisting with the data collection.

\section{Competing interests}

The author declares that he has no financial or personal relationships that may have inappropriately influenced him in writing this article.

\section{References}

Al-Tit, A. A., \& Hunitie, M. (2015). The mediating effect of employee engagement between its antecedents and consequences. Journal of Management Research, 7(5), 47-62. https://doi.org/10.5296/jmr.v7i5.8048

Alvi, A. K., \& Abbasi, A. S. (2012). Impact of organisational justice on employee engagement in baking sector of Pakistan. Middle-East Journal of Scientific Research, 12(5), 643-649.

Al-Zawahreh, A., \& Al-Madi, F. (2012). The utility of Equity Theory in enhancing organizational effectiveness. European Journal of Economics Finance and Administrative Sciences, 46, 158-170.

Bakker, A. B., Schaufeli, W. B., Leiter, M. P., \& Taris, T. W. (2008). Work engagement: An emerging concept in occupational health psychology. Journal Work and Stress, 22(3), 187-200. https://doi.org/10.1080/02678370802393649

Bettencourt, L. A., \& Brown, S. W. (1997). Contact employees: Relationships among workplace fairness, job satisfaction and pro-social behavior. Journal of Retailing, 73(1), 10-17. https://doi.org/10.1016/S0022-4359(97)90014-2

Biswas, S., Varma, A., \& Ramaswami, A. (2013). Linking distributive and procedural justice to employee engagement through social exchange: A field study in India. Chicago, IL: Loyola eCommons, School of Business: Faculty Publications and Other works.

Boonzaier, B., Ficker, B., \& Rust, B. (2001). A review of research on the job characteristics model and the attendant job diagnostic survey. South African Journal of Business Management, 32(1), 11-34.

Brunetto, Y., Teo, S. T. T., Shacklock, K., \& Farr-Wharton, R. (2012). Emotiona intelligence, job satisfaction, well-being and engagement: Explaining organisational commitment and turnover intentions in policing. Human Resource Management Journal, 22(4), 428-441. https://doi.org/10.1111/j.1748-8583. 2012.00198.x

Cohen, J. (1988). Statistical power analysis for the behavioural sciences (rev. ed.) Orlando, CA: Academic Press.

Colquitt, J. A. (2001). On the dimensionality of organisational justice: A construct validation of a measure. Journal of Applied Psychology, 86, 386-400. https://doi. org/10.1037/0021-9010.86.3.386

Creswell, J. W. (2003). Research design; qualitative, quantitative, and mixed methods approaches (2nd edn.). London, UK: Sage Publications.
Dajani, M. A. Z. (2015). The impact of employee engagement on job performance and organisational commitment in the Egyptian banking sector. Journal of Business and Management Sciences, 3(5), 138-147.

Gelens, J., Hofmans, J., Dries, N., \& Pepermans, R. (2014). Talent management and organisational justice: Employee reactions to high potential identification. Human Resource Management Journal, 24(2), 159-175. https://doi.org/10.1111/17488583.12029

Greenberg, J. (2011). Behavior in organisations (10th edn.). Cape Town, South Africa: Pearson.

Harter, J. K., Schmidt, F. L., \& Hayes, T. L. (2002). Business-unit level relationship between employee satisfaction, employee engagement, and business outcomes: A meta-analysis. Journal of Applied Psychology, 87, 268-279. https://doi. org/10.1037/0021-9010.87.2.268

Ikhide, S. (2000). Efficiency of commercial banks in Namibia. Bank of Namibia Occasional Paper, Number 4. Windhoek, Namibia: Bank of Namibia Research Department. Retrieved from https://www.bon.com.na/CMSTemplates/Bon/Files/ bon.com.na/b8/b8b60638-88ce-457b-a0c2-554765376e70.pdf

Judge, T. A., \& Kammeyer-Mueller, J. D. (2012). Job attitudes. Annual Review of Psychology, 63, 341-367. https://doi.org/10.1146/annurev-psych-120710-100511

Kassahun, T. (2005). Level of organisational commitment: Its correlates and predictors. Indian Journal of Industrial Relations, 41(1), 29-63.

Kim, T., Lin, X., \& Leung, K. (2015). A dynamic approach to fairness: Effects of temporal changes of fairness perceptions on job attitudes. Journal of Business and Psychology, 30, 163-175. https://doi.org/10.1007/s10869-013-9341-6

Lawson, K. J., Noblet, A. J., \& Rodwell, J. J. (2009). Promoting employee wellbeing: The relevance of work characteristics and organisational justice. Health Promotion International, 24(3), 223-233. https://doi.org/10.1093/heapro/dap025

Lopez-Cabarcos, M. A., Pinho, A. I. M., \& Vazquez-Rodriguez, P. (2014). The influence of organisational justice and job satisfaction on organisational commitment in Portugal's hotel industry. Cornell Hospitality Quarterly, 56(3), 258-272. https:// doi.org/10.1177/1938965514545680

Marais, E., De Klerk, M., Nel, J. A., \& De Beer, L. (2014). The antecedents and outcomes of work-family enrichment amongst female workers. South African Journal of Industrial Psychology, 4O(1), 1-14. https://doi.org/10.4102/sajip.v40i1.1186

McAuliffe, E., Manafa, O., Maseko, F., Bowie, C., \& White, E. (2009). Understanding job satisfaction amongst mid-level cadres in Malawi: The contribution of organisational justice. Reproductive Health Matters, 17(33), 80-90. https://doi. org/10.1016/S0968-8080(09)33443-6

Okediji, A. A., Etuk, A. S., \& Anthony, O. U. (2011). Influence of perceived co-worker involvement and supervisory support on job satisfaction. Ife PsychologylA, 19(1), 543-557.

Pieters, W. R. (2015). Psychological empowerment and how it impacts on job satisfaction and organisational commitment of staff members at the University of Namibia (UNAM). Namibia Journal of Managerial Sciences, 1(2), 98-120.

Pinikahana, J., \& Happell, B. (2004). Stress, burnout and Job satisfaction in Rural Psychiatric nurses: A Victorian study. Australian Journal of Rural Health, 12, 120-125. https://doi.org/10.1111/j.1440-1854.2004.00572.x

Rasheed, A., Khan, S., \& Ramzan, M. (2013). Antecedents and consequences of employee engagement: The case of Pakistan. Journal of Business Studies Quarterly, 4(4), 183-200.

Resi, H. T., \& Judd, C. M. (2000). Handbook of research methods in social and personality psychology. Cambridge: Cambridge University Press.

Rothbard, N. P., \& Patil, S. V. (2012). Being there: Work engagement and positive organizational scholarship. In K. S. Cameron \& G. M. Spreitzer (Eds.), The Oxford handbook of positive organizational scholarship (pp. 56-68). New York, NY Oxford University Press.

Rothmann, S. (2008). Job satisfaction, occupational stress, burnout and work engagement as components of work-related wellbeing. South African Journal of Industrial Psychology, 34(3), 11-16. https://doi.org/10.4102/sajip.v34i3.424

Rothmann, S. \& Jordaan, G. M. E. (2006). Job demands, job resources and work engagement of academic staff in South African higher education institutions. South African Journal of Industrial Psychology, 32(4), 87-96. https://doi. org/10.4102/sajip.v32i4.247

Rothmann, S., \& Rothmann, S. (2010). Factors associated with employee engagement in South Africa. South African Journal of Industrial Psychology, 36(2), 1-12. https://doi.org/10.4102/sajip.v36i2.925

Saks, A. M. (2006). Antecedents and consequences of employee engagement. Journal of Managerial Psychology, 21(7), 600-619. https://doi.org/10.1108/02683940 610690169

Schaufeli, W. B., Bakker, A. B., \& Salanova, M. (2006). The measurement of work engagement with a short questionnaire: A cross-national study. Educational and Psychological Measurement, 44(4), 701-716. https://doi.org/10.1177/00131 64405282471

Sehunoe, N., Viviers, R., \& Mayer, C. (2015). Job satisfaction, organisational commitment and work engagement in an insurance company. South African Journal of Labour Relations, 39(2), 123-144.

Simons, J. C., \& Buitendach, J. H. (2013). Psychological capital, work engagement and organisational commitment amongst call centre employees in South Africa. South African Journal of Industrial Psychology, 39(2), 1-12. https://doi.org/10.4102/ sajip.v39i2.1071

Smit, W., Stanz, K., \& Bassin, M. (2015). Retention preferences and the relationship between total rewards, perceived organisational support and perceived supervisory support. South African Journal of Human Resource Management, 13(1), 1-13. https://doi.org/10.4102/sajhrm.v13i1.665 
Soltis, S. M., Agneessens, F., Sasovova, Z., \& Labianca, G. (2013). A social network perspective on turnover intentions: The role of distributive justice and social support. Human Resource Management, 52(4), 561-584. https://doi.org/ 10.1002/hrm.21542

SPSS (2016). SPSS 24.0 for Windows. Chicago, IL: SPSS Incorporated.

Steyn, H. S. (1999). Praktiese betekenisvolheid: Die gebruik van effekgroottes. Wetenskaplike bydraes - Reeks B: Natuurwetenskappe Nr. 117. Potchefstroom: $\mathrm{PU}$ vir $\mathrm{CHO}$.
Strom, D. L., Sears, K. L., \& Kelly, K. M. (2013). Work engagement: The roles of organisational justice and leadership style in predicting engagement among employees. Journal of Leadership and Organisational Studies, 20(5), 1-12.

Tessema, D. (2014). Determinants of employee engagement in commercial bank of Ethiopia Addis Ababa area. Unpublished Master's degree in Business administration in management. Addis Ababa University, Ethiopia.

Weiss, D. J., Davis, R. V., England, G. W., \& Lofquist, L. M. (1967). Manual for the Minnesota satisfaction questionnaire. Minneapolis, MN: University of Minnesota, Industrial Relations Centre. 